\title{
Inconsciente político: por uma hermenêutica social
}

\author{
Thomaz Abreu ${ }^{1}$
}

\begin{abstract}
RESUMO: Es te artigo visa dar alguns contornos da noção de "inconsciente político", de Fredric Jameson, considerando-a uma hermenêutica social, porquanto tal noção reúne personagens conceituais tanto da tradição marxista quanto da psicanálise, de modo a propor uma nova atividade interpretativa vinculada ao coletivo e politicamente fundamentada. Nesse contexto, podemos, também, pensar uma categoria adicional para os horizontes de análise.
\end{abstract}

PALA VRAS-CHA VE: literatura; inconsciente; política; hermenêutica; permanência

ABSTRACT: This article aims at presenting some contours of the notion of "political unconscious", by Fredric Jameson, considering this idea a social hermeneutics, provided that such notion reunites conceptual characters of Marxism and Psychoanalysis, posing a new act of interpreting, which is politically grounded and connected to collectivity. According to this context, we can also reflect upon an additional category for the hermeneutic analysis.

KEYW ORDS: literature; unconscious; politics; hermeneutics, persistence

Pode-se falar que Jameson advoga a favor de uma ontologia do social a qual se mostra como uma hermenêutica contra a opressão que reprime o conteúdo político do texto. De acordo com o filósofo, há uma perspectiva política que oferece tanto o horizonte absoluto de toda a leitura e toda a interpretação quanto uma filosofia da história capaz de respeitar a especificidade e diferença radical do passado sociocultural. Trata-se do marxismo, na medida em que ele unifica os acontecimentos humanos, os quais são vistos sob uma trama incompleta, qual seja, a história da luta de classes. Dado que essa história, cujos traços são passíveis de constatação, pode ser oculta e reprimida na superfície do texto, é imperativo que uma doutrina de um inconsciente político revele-se como uma hermenêutica peculiar, na qual se resgate, para o texto, o conteúdo político deste, o qual, reprimido na sua superfície, jaz inconscientemente. Dessa forma, podemos dizer que o campo social tem seu ser na história, na luta ininterrupta do

\footnotetext{
1 Mestrando em literatura, com uma pesquisa intitulada de "Sentidos e significados da personagem 'inominada' no Avalovara de Osman Lins", thomazabreu28@gmail.com, estudante da UnB.
} 
opressor contra o oprimido, a qual não é reduzida a interpretações atuais extrapolativas e que, no "inconsciente" do texto, acaba por revelar o motivo político de libertá-la da repressão que, aí, sofre, imperativo esse da nova hermenêutica ${ }^{2}$.

Tal hermenêutica não é terapêutica, porquanto o inconsciente do qual ela trata é, necessariamente, politizado, o que oferece um veio crítico contra a psicanálise. Dado que Freud, responsável pela descoberta do "inconsciente", evitava que se analisassem os vínculos políticos dos conteúdos do inconsciente ${ }^{3}$, a hermenêutica defendida por Jameson não se confunde com a terapia, a qual ora tinha o foco na interpretação do inconsciente, decifrando-o, ora nas resistências do doente, ora na neurose de transferência ${ }^{4}$, porquanto tal hermenêutica objetiva reafirmar o conteúdo político do texto, contra as reduções, as quais reprimem esse conteúdo, sem, contudo, partir do texto para tornar inexequíivel o ato interpretativo. Dessa forma, afirmamos que a hermenêutica em questão pode ser entendida como uma interpretação política do inconsciente do texto, na media em que resgata, no texto, o seu conteúdo político inconsciente. Assim,

(...) de nosso atual ponto de vista, o ideal de uma análise imanente do texto, de um desmantelamento ou desconstrução de suas partes e de uma descrição de seu funcionamento e mau funcionamento, implica menos uma total anulação de toda atividade interpretativa do que a exigência de elaboração de um modelo hermenêutico novo (...) (JAMESON, 1992, p. 20).

O argumento de Jameson a favor de tal hermenêutica escrutina a posição de Althusser acerca do problema epistemológico da economia política proposto por Marx. Para Althusser, dado que esse problema seja a possibilidade de definição do conceito de causalidade estrutural, pode-se pensar com a filosofia clássica, que apresenta a efetividade de tipo mecanicista e a efetividade de tipo expressivo, ou com Marx, a efetividade como causalidade estrutural. Para Jameson, a causalidade mecânica, que não

\footnotetext{
${ }^{2}$ Se o texto possui um "inconsciente", podemos pensar que ele é lacunar (FREUD, 2006, p. 19). Mas a noção de Jameson é politizada, o que acaba por afastá-lo de u ma referência, apenas, freudiana.

3 Veja-se, por exemplo, em Materialismo dialético e psicanálise, quando Reich afirma, em nota de rodapé, que "(...) a teoria da compulsão de repetição para além do princípio do prazer era u ma hipótese que teria surgido especialmente com o objetivo de dessexualizar o próprio aparelho psíquico" (REICH, 1977, pp. 96-97), sendo que, por outro lado, a sublimação depende do processo social decisivamente, "(...) de tal modo que a libido sublimada, como força de trabalho, se transforma em força produtiva" (REICH, 1977, p. 107). Parece-nos que uma interpretação reichiana do "inconsciente" pode se adequar mu ito bem à vinculação desse termo a u ma perspectiva política.

${ }^{4} \mathrm{Tal}$ é o balanço que Freud, em Além do princípio de prazer, apresenta como as diferentes metas imediatas da técnica psicanalítica para se atingir o objetivo terapêutico (FREUD, 2006, pp. 144-155).
} 
conseguia pensar a efetividade de um todo a partir de seus elementos, não é, apenas, uma forma da falsa consciência, mas um sintoma de contradições objetivas que ainda permanecem nos dias atuais, sendo uma das leis que regem a vida social e cultural reificada. Dessa forma, podemos dizer que a categoria da efetividade mecânica é heuristicamente importante, já que retém uma validade sincrônica.

Quanto à efetividade de tipo expressivo, ela é alegórica e, assim, resgata a teoria da interpretação medieval. Se entendermos, com Althusser, que a causalidade expressiva é uma relação em que o todo seja reduzido a uma essência interior, de modo que o princípio dessa essência se encontra presente em cada ponto do todo, essa causalidade é uma alegoria interpretativa, pois, explica Jameson, uma seqüência de eventos é lida em termos de uma narrativa-mestra oculta. Em se tratando de sistemas alegóricos, o autor de $O$ inconsciente político coloca que o sistema medieval oferece quatro sentidos para um texto, de maneira que esse sistema é original, pois abre o texto para múltiplos significados, preservando a literalidade do texto original e, ainda, é o mesmo sistema instrutivo para a nossa contemporaneidade, já que, equacionando essa multiplicidade de sentidos, não opõe liberdade de interpretação a interpretações fechadas, mas as equaciona. De qualquer forma, a causalidade expressiva, com seu veio alegórico, não se refere simplesmente ao idealismo hegeliano, como quer Althusser, mas, pondera Jameson, a quaisquer interpretações que assimilem níveis de interpretação uns aos outros. Dessa forma, podemos afirmar que a causalidade expressiva é uma forma de interpretação alegórica, além de se encontrar, tal com a causalidade mecânica, dentro da nossa realidade histórica ${ }^{5}$.

A seguir Jameson, Althusser pode ter sua formulação acerca da história e sua crítica à causalidade expressiva revisadas de maneira positiva. Jameson explica que Althusser não chega à conclusão segundo a qual a História é um texto, ou que o "referente" não existe, ao contrário, dado que a história seja "casa ausente", pode-se dizer que ela não é um texto, nem narrativa, mas que nos é acessível, apenas, sob a forma textual. Quanto à causalidade, o alvo de Althusser não é a noção de "mediação", mas, explica Jameson, a noção estrutural da "homologia", "isomorfismo" ou

\footnotetext{
${ }^{5}$ Jameson apresenta os quatro sentidos da exegese cristã: o anagógico, relacionado a uma leitura política ("significado" coletivo a História); o moral, uma leitura psicológica relacionada ao sujeito individual; o alegórico, isto é, uma chave alegórica ou código interpretativo; e o literal, relacionado ao referente histórico ou textual. A inda que os dois primeiros não nos sejam acessíveis hoje, o esquema, tomado com um todo, não deixa de ser instrutivo. Sistemas interpretativos alegóricos também se encontram presentes no marxis mo vulgar, com sua divisão entre superestruturas e infra-estrutura. (JAMESON, 1992, pp.2829).
} 
"paralelismo estrutural", a qual, além de estática e anti-histórica, postula uma mesma estrutura para realidades bastante diferentes (como a situação social, a posição filosófica e a prática verbal, quando relacionadas a uma suposta "mesma" estrutura). Dessa forma, a história não recebe a apreciação que pode ser vista em variantes de pós-modernismos os quais afirmam que ela só é texto, e a causalidade expressiva pode ser reconsiderada, sem se posicionar em oposição à "mediação" 6 .

Uma causalidade estrutural opõe-se à causalidade expressiva. De acordo com Jameson, a "totalidade", tal como Lukács a entende, é um método crítico e negativo, que pode servir de instrumento para desmascarar as "estratégias de contenção", confrontando-as com o ideal de totalidade que elas mesmas reprimem. Essa noção de "totalidade" recai, explica Jameson, na noção althusseriana da História como "causa ausente", uma vez que a "totalidade" não é suscetível de representação, nem é acessível sob a forma de uma verdade essencial. A totalidade, no âmbito do expresso, valoriza, contudo, a forma orgânica, uma vez que projeta uma obra de arte como um todo ordenado. Dado que a causalidade expressiva deve, tal como afirma Jameson, buscar falhas e descontinuidades dentro da obra, essa causalidade estrutural terá como objetivo a explosão do texto, de modo que ele, de aparentemente unificado, revele-se em elementos conflitantes e contraditórios, já que tal causalidade busca encontrar falhas e descontinuidades dentro da obra. Dessa forma, podemos entender que a causalidade estrutural focaliza o que há de rarefeito, descontínuo, esquizo frênico na obra.

Essas três causalidades não são, contudo, estanques, unificando-se numa crítica totalizadora cuja "condição transcendental" é a imanência à dialética. Jameson explica que pelo conceito de "cultura", seja com Marx ou Althusser, a exegese de um texto não se limitará ao que lhe é descontínuo e heterogêneo, pois a constatação desses elementos é tão-somente um momento exegético, cuja interpretação deve avançar para interligar as heterogeneidades e incomensurabilidades do texto, estabelecendo-se, assim, uma crítica totalizadora. Embora essa crítica totalizadora recorra a esferas e/ou níveis exteriores ao texto, ela é, explica Jameson, apenas, provisoriamente, transcendente, porquanto, dialeticamente, o conteúdo aparentemente externo é re-inserido no processo de leitura. Dessa forma, a crítica totalizadora tem como condição de possibilidade reunir,

\footnotetext{
${ }^{6}$ De fato, a "mediação" é, para Jameson, u ma forma de causalidade expressiva (JAMESON, 1992, p.37).
} 
dialeticamente, fatores internos e externos ao texto, não sendo possível que ela vá além, nem aquém, dessa re-inserção dialética de elementos exteriores ao texto ${ }^{7}$.

A nova hermenêutica que Jameson erige não se confunde com o sistema interpretativo mais influente dos tempos recentes. De acordo com o filósofo, esse sistema é a psicanálise, cujo estímulo, de tão forte, possibilitou a colocação do modelo freudiano a serviço de sistemas totalmente distintos. Deve-se notar, ressalta Jameson, que é o "desejo", ou seja, a satisfação do anseio, o eixo central em torno do qual gira esse sistema interpretativo. Tal sistema, contudo, é, apenas, indiretamente útil ao "inconsciente político", pois, explica Jameson, o desejo permanece enclausurado numa problemática do sujeito individual, o que muda com Lacan, que leva essa problemática ao questionamento, mas, ressalta Jameson, a repressão e a revolta, eventos narrativos da teoria do desejo, deverão ser compatíveis com uma perspectiva marxista. Dessa forma, podemos dizer que o "inconsciente político" não se confunde com a teoria do desejo, em Freud, já que ela isola o indivíduo em sua biografia, nem com a reescritura lacaniana de Freud, já que o desejo deve ser compatível com a liberação e a transfiguração libidinal, proporcionadas pelo marxismo ${ }^{8}$.

\footnotetext{
${ }^{7}$ Falamos, neste parágrafo, de "condição transcendental", entendo esse termo tal co mo Kant explica o modo de conhecimento de objetos, o qual deve ser possível a priori (KANT, 2000, p. 65), ou seja, co mo condição de possibilidade. Ademais, parece-nos oportuno lembrar que a operação de totalização dos elementos heterogêneos assemelha-se à "apreensão verdadeira" descrita por Hegel na Fenomenologia do espírito, pois, em comparação à interligação entre as coisas, de tal modo que "Se a coisa é determinada mais exatamente como este pedaço de papel, então todo e cada papel é um este pedaço de papel (...)" (HEGEL, 1974, p. 68), podemos entender que os elementos heterogêneos de um texto, que são singulares, também não são isolados, mas, imanentemente, são interligados entre si, além de o serem com outros que lhes são exteriores, com os quais passam a travar relações dialéticas. A propósito, é digno de nota que o pensamento de Hegel é colocado, por Jameson, em termos totalmente distintos dos que ele costuma ser apresentado, como fica claro no atinente à "teoria da identidade", contra a qual, a seguir Jameson, Hegel investe (JAMESON, 1992, p. 47).

8 Jameson, no início do capítulo "A interpretação", do qual temos nos ocupado, afirma que o espírito do seu trabalho contém a força do argumento de Deleuze e Guattari, mostrado no livro Anti-Édipo, já que esses autores pretendem atacar a interpretação freudiana, que reduz a totalidade rica e aleatória da realidade a termos pré-limitados da narrativa familiar (JAMESON, 1992, p. 19). Mas, diferentemente desses autores, Jameson interessa-se pela elaboração de um modelo hermenêutico novo (JAMESON, 1992, p. 20). Há, portanto, um diálogo crítico com a filosofia de Deleuze-Guattari, que também pode ser visto no atinente à crítica contra a teoria do desejo em Freud. Nesse sentido, sabemos, pelo mesmo liv ro citado de Deleuze e Guattari, como esses pensadores discordam da descrição freudiana do inconsciente, pois, explicam eles, "As noções fundamentais de economia do desejo, trabalho e investimento conservam toda a sua importância - na psicanálise -, mas subordinadas agora às formas de um inconsciente expressivo e já não às formações do inconsciente produtivo" (DELEUZE e GUATTARI, 1966, p. 57). Embora Jameson poss a concordar com a crítica desses autores contra a subordinação do desejo à esfera familiar, diferentemente deles, para os quais Lacan, assim como Freud e Jung, permanece no dogma da psicanálise, qual seja, a figura do "papai-mamãe-eu", permitindo a apropriação, pelo "Édipo", de toda "produção desejante" e de todas as forças produtivas do desejo (DELEUZE e GUATTARI, 1996, p. 58), Jameson, contudo, reconhece, numa leitura sutil, a postura lacaniana como um desvio subversivo da hermenêutica freudiana, já que, com Lacan, lê-se o questionamento da problemática do sujeito individual e da psicobiografia individual, “(...) trazendo para o primeiro plano a categoria do sujeito e estudando o
} 
É imperativo que o "inconsciente político" reflita sobre o desejo, tendo como propedêutica o trabalho de Northrop Frye. Se, como diz Jameson, é danoso que o desejo fique encerrado no sujeito individual, faz-se necessário buscar alternativas às categorias individuais e aos modelos de interpretação, pois transcender essas categorias e modelos é “(...) de muitas formas, a questão fundamental para qualquer doutrina do inconsciente político, da interpretação em termos do coletivo ou associativo" (JAMESON, 1992, p. 62). A seguir Jameson, o sistema de arquétipos de Frye é interessante e radical, pois concebe a formação da cultura em termos sociais e estabelece consequiências interpretativas sociais tomando a religião como representação coletiva.

O trabalho propedêutico de Frye é, contudo, falacioso, tendo em vista a hermenêutica social do "inconsciente político". Dado que, para Frye, as figuras religiosas tornam-se espaço simbólico de auto-celebração da coletividade, a literatura deveria ser lida como meditação simbólica sobre o destino da comunidade, mas Frye, explica Jameson, permite que o vínculo político se rompa, na medida em que, nas quatro fases, inscritas na sua "teoria dos símbolos", existe uma figuração contida no arranjo dos níveis alegóricos a qual não implica nada além do corpo cósmico, deixando, assim, o conteúdo coletivo da imagem limitado a termos apenas individuais. Dessa forma, o "inconsciente político" vai de encontro a essa teoria, já que ele elabora uma hermenêutica social, na qual imagens de revolução libidinal e da transfiguração do corpo tornam-se figuras coletivas ${ }^{9}$.

Jameson ocupa-se com as perspectivas do marxismo no sentido de serem precondições necessárias à compreensão literária. Nesse sentido, o filósofo apresenta três horizontes para a inteligibilidade dos textos literários. Em primeiro lugar, o objeto de estudo é tomado como expressão literária individual, mas apreendido como ato simbólico. Dado o modelo interpretativo do mito de Claude Lévi-Strauss, a eficácia simbólica de um texto, explica Jameson, deve ser orientada de maneira a apreendê-lo como uma estrutura determinada de contradições, já que a narrativa individual deve ser apreendida como a resolução imaginária de uma contradição real. Assim, a forma

processo por meio do qual essa realidade psíquica - o consciente - (...) tornou-se rigorosa e impôs limites à noção freudiana de satisfação individual" (JAMESON, 1992, p. 60).

${ }^{9}$ Jameson explica que Frye reestrutura os quatro níveis medievais de interpretação em termos de quatro fases, chamadas por Frye de: literal e descritiva; formal; mítica ou arquetípica; e anagógica. Frye, contudo, não segue o sistema cristão, que, explica Jameson, é, essencialmente, histórico e político (JAMESON, 1992, p. 67). 
estética ou narrativa deve ser vista como um ato ideológico, cuja função é dar soluções inventadas ou formais para contradições insolúveis ${ }^{10}$.

Ainda nesse primeiro horizonte, o texto literário possui camadas sociais as quais coordenam, metodologicamente, um método dialético e uma semiótica. A seguir Jameson, a interpretação, nesse primeiro momento, é uma reescritura do texto literário, na medida em que ele possa ser visto como reescritura de um subtexto histórico ou ideológico anterior, o qual tem sempre de ser construído, ou reconstruído. Mas, explica o filósofo, esse subtexto, local da ideologia, é secundário em relação a outro subtexto, que é local da contradição social. Nesse agremiado de subtextos, pode-se reformular o retângulo semiótico greimasiano com um método dialético, na medida em que a articulação das oposições binárias é vista como projeção de uma contradição social. Assim, podemos dizer que a interpretação de um texto literário é dialético-semiótica, o que faz a análise semiótica prestar serviços à dialética ${ }^{11}$.

A análise semântica é necessária, mas não é suficiente, o que implica a noção de “classe social" vinculada à análise literária. Passando ao segundo horizonte proposto por Jameson, o filósofo explica que se deve demonstrar o "ideologema”, ou seja, “(...) a menor unidade inteligível dos discursos coletivos essencialmente antagônicos das classes sociais" (JAMESON, 1992, p. 69), já que o horizonte semântico do texto literário ampliou-se, de maneira a incluir a ordem social. As classes sociais, contudo, devem ser definidas como antagônicas, de modo que sua forma constitutiva seja sempre a oposição entre uma classe dominante e outra trabalhadora, porquanto, dessa forma, o modelo marxista de classes diferencia-se da análise sociológica convencional, que permite que um subgrupo possa ser estudado isoladamente. Dessa forma, podemos dizer que esse segundo horizonte estabelece o ponto de vista relacional do anta gonismo entre

\footnotetext{
${ }^{10}$ O texto básico de Claude Lévi-Strauss ao qual Jameson se refere é "O estudo Estrutural do Mito", no qual o antropólogo analisa a decoração facial única dos índios Cadivéu (JAMESON, 1992, p. 70).

${ }^{11}$ É interessantíssima essa reunião de dialética e semiótica, u ma vez que, assim, a dialética, que é tanto um conceito ontológico quanto epistemológico, estende-se aos signos semiotizados, evitando que eles se tornem, meramente, auto-referentes. Essa é uma postura que também revela o diálogo crítico entre Jameson e Deleu ze-Guattari, já que, como fica claro no livro O que é a filosofia?, esses autores apostam tanto na auto-referência do conceito filosófico (DELEUZE e GUATTARI, 1992, p. 26) quanto na obra de arte como não mais do que um existente em si (DELEUZE e GUATTARI, 1992, pp. 144-145). Aqui, poderíamos, então, a essa auto-referência e a essa existência em si, opor as relações dialéticas nos três horizontes propostos por Jameson, os quais são criações conceituais deste filósofo as quais se definem numa relação necess ariamente social da obra de arte.
} 
as classes como meio heurístico privilegiado que retira a interpretação de uma análise meramente textual ${ }^{12}$.

O terceiro horizonte implica a reformulação dos conceitos de "modo de produção" e "revolução cultural". Nesse horizonte, a leitura de textos deve considerar o âmbito da "ideologia da forma”, isto é, “(...) as mensagens simbólicas a nós transmitidas pela coexistência de vários sistemas simbólicos que são também traços ou antecipações dos modos de produção" (JAMESON, 1992, p. 69). Isso posto, faz-se necessário rever o conceito de "modo de produção", já que se pode considerar que toda sociedade historicamente existente é constituída pela sobreposição e coexistência de vários modos de produção, ao mesmo tempo, incluindo vestígios de outros. Dessa forma, explica Jameson, pode-se falar de uma "revolução cultural", quando essa coexistência torna-se, visivelmente, antagônica ${ }^{13}$.

A "revolução cultural" é o objeto específico do terceiro horizonte. Dado que, no texto, seja revelada a dinâmica dos sistemas e signos de vários modos de produção, o texto é reestruturado, na medida em que seja possível registrá-los e apreendê-los. Dado que, em um processo artístico e na formação social, a "ideologia da forma" se refere à contradição de mensagens específicas dos vários sistemas de signos coexistentes, a análise dessa ideologia não se confunde com a denúncia da centralização analítica na forma, em detrimento de questões sociais e históricas, pois a análise da "ideologia da forma" deve revelar formas de estruturas arcaicas e recentes de alienação. Assim, podemos dizer que dar visibilidade a formas de alienação pode ser uma maneira de resistir à reificação, o que vincula a reestruturação do texto à História como “(...) inexorável forma dos acontecimentos"(JAMESON, 1992, p. 93) ${ }^{14}$.

Esses três horizontes podem guardar semelhanças com a "hermenêutica do Dasein", as quais não se confundem com a hermenêutica do inconsciente político ${ }^{15}$. A

\footnotetext{
12 A noção de "ideologema", assim como a de "ideologia da forma", que estará presente no terceiro horizonte, é criação conceitual jamesoniana que recusa, justamente, uma teoria de auto-referência para a análise de textos literários.

13 O conceito de "ideologia da forma" não é estático, pois recebe outras versões que aprofundam essa primeira, como acontece quando, por exemplo, tal conceito é aprofundado por meio da questão dos "modos de produção" em relação aos signos coexistentes num processo artístico (JAMESON, 1992, pp. 90-91).

${ }^{14}$ A História, as sim concebida, é, para Jameson, o reino da "Necessidade", impondo limites ao indivíduo, à prática coletiva, mas apreendida, apenas, indiretamente, ou seja, por seus efeitos.

${ }^{15}$ Heidegger, talvez, pre fira o termo "analítica do Dasein" para se referir aos caracteres específicos de ser do Dasein enquanto Da-sein em co mparação com os caracteres de ser do que não temo caráter do Dasein, tal co mo ele tentou mostrar em Ser e tempo (HEIDEGGER, 2001, p. 148).
} 
palavra "hermenêutica" possui vários sentidos ${ }^{16}$, sendo, assim, um conceito filosófico de longa história. É fulcral, contudo, o sentido que Heidegger atribui ao termo, pois, entende o autor de Ser e tempo, ela não se refere a regras de interpretação textual, nem à ciência ou metodologia, mas à própria realidade humana, de modo que a compreensão é, junto com a disposição, um dos existenciais fundamentais “(...) que constituem o ser do pré, ou seja, a abertura do ser-no-mundo. Toda compreensão guarda em si a possibilidade de interpretação..." (HEIDEGGER, 2001, pp. 218-219). Dado que a hermenêutica social do inconsciente político não se refere, apenas, a uma leitura de texto, ou técnica de interpretação, porquanto se vincula com o nosso modo de ser no mundo, a mundividência que, deste, temos, ela é, assim, caudatária da "virada hermenêutica" heideggeriana. Esse parentesco com Heidegger pode, contudo, não ir mais longe. Se a "hermenêutica social" do inconsciente político não se restringe a uma técnica de leitura de textos, ela se mostra engajada, porquanto seu alvo social é claramente estabelecido. Esse engajamento, por sua vez, é politicamente orientado, já que “(...) quando trazemos para a superfície do texto a realidade reprimida e oculta dessa história fundamental - a da luta de classes - que a doutrina de um inconsciente político encontra sua função e sua necessidade" (JAMESON, 1992, p. 18).

À guisa de conclusão, diremos que essa "hermenêutica social" complica-se na situação que a literatura ocupa em países periféricos, onde adquire peculiar "permanência"17. A literatura é histórica de duas maneiras, pois, explica Bastos, diz aos leitores a história de que é parte e é um elemento de reprodução da matriz ideológica da subjetividade. Assim, a literatura contribui para preservar as condições ideológicas da hegemonia burguesa, pois "sua permanência (e sua mundialização) é a permanência da matriz ideológica em que ela foi gerada (e aqui ela é produto) e que ela ajuda a preservar (como produtora de história)" (BASTOS, 1998, p. 127). Por outro lado, há "fatores de emancipação", formulados na modernidade, que ensejam a auto-crítica da literatura enquanto instituição. Assim, a literatura tanto reproduz sua matriz ideológica quanto se faz como crítica da cultura.

\footnotetext{
${ }^{16}$ Palmer, por exemp lo, arrola três orientações para o termo em questão, enquanto "dizer", "explicar" e "traduzir", além de especificar a "hermenêutica" enquanto teoria da exegese bíblica, metodologia filológica, ciência da compreensão lingüística, metodologia para as "geisteswissenschaften", fenomenologia do Dasein e fenomenologia da compreensão existencial (PALMER, 1996, pp. 23-54).

${ }^{17}$ Usaremos a noção de "permanência" que é desenvolvida pelo crítico literário e filósofo Hermenegildo Bastos em artigo intitulado de "A permanência da literatura (direções da prática literária na era do multiculturalismo e da indústria cultural)", publicado na revista Cerrados, nº8, ano 7, 1998.
} 
A seguir Bastos, há várias dicotomias surgidas na modernidade, mas duas são fundamentais, quais sejam, verdade/falsidade e objetividade/subjetividade, pois os elementos iniciais desse pares caracterizam a ciência, ao passo que a literatura é caracterizada pelos outros elementos, falsidade e subjetividade, os quais foram aceitos pela institucionalização da literatura. Por outro lado, a literatura pode questionar essas dicotomias, na medida em que problematiza a sua ficcionalidade e a subjetividade. Isso posto, a literatura que empreende tal questionamento configura um desejo de autoextermínio, mas essa literatura, também, acata as determinações que pretende destruir. Dessa forma, a literatura é ambivalente ${ }^{18}$.

Bastos entende que o texto literário é um "discurso de reutilização" cuja autorepresentação aponta para a estrutura social que a tornou possível e necessária, já que o fato de esse discurso apontar para as suas marcas textuais decorre da utilização que os participantes da comunidade literária fazem desse discurso. Isso implica relações interculturais ligadas à literatura, pois ela não é universal, dada a diferença no repertório do que se afirma, hoje em dia, ser a literatura, em comparação com ao que se dizia em outras épocas, além do fato de a literatura ser dependente de um dado tipo de prática discursiva. Dessa forma, a literatura carece de se legitimar ${ }^{19}$.

O que permitiu a literalização de outras práticas expressivas foi, ressalta Bastos, a europeização do mundo. Essa europeização implica o problema do colonialismo, já que ela é o processo de imposição da modernidade. A modernidade, contudo, também enseja uma dupla crítica, da modernidade e da modernização imposta, já que, com a modernidade, a colonização torna-se um problema e é caracterizada com violência. Assim, há uma contradição fundamental: "se a preservação da literatura se insere no movimento geral de reprodução das condições de poder, ela é também um espaço de crítica e de resistência à instrumentalização"(BASTOS, 1998, p. 133).

A periferia não é, adverte Bastos, passiva, na história da europeização, pois todo centro, para firmar-se como tal, precisa criar sua periferia, de modo que os colonizados acabamos por dar à Europa a condição de centro. Essa constitutividade periférica do centro está representada na própria polifonia do romance, a qual, explica Bastos, permite que se ouçam vozes que nele, e fora dele, contradizendo-se e antagonizando-se. Desse modo, a literatura pode estabelecer um antagonismo frente à história dominante.

\footnotetext{
${ }^{18}$ Bastos exemplifica que Dom Quixote é, ao mesmo tempo, u ma obra que marca o autoquestionamento da literatura e uma das "grandes obras" da literatura (BASTOS, 1998, p. 130).

${ }^{19}$ Bastos infere da literatura, enquanto prática discursiva, sem legitimação, u ma dimensão metaliterária da literatura (BASTOS, 1998, p. 133).
} 
A literatura está em condições dilemáticas de acriticidade, mas ela permanece, em seu autoquestionamento. A seguir Bastos, a discussão acerca da autonomia da arte pode apresentar uma estrutura dilemática, pois, havendo duas alternativas, quais sejam, a literatura manter-se como autônoma, ou dissolver-se na vida cotidiana, a criticidade e o combate da literatura são refreados em ambos os casos. Ainda assim, essa aporia é, também, a saída, pois, explica Bastos, se, por um lado, a literatura permanece, reafirmando valores sacralizados, por outro, ela se deseja como diferença, a qual pode ser encontrada na elaboração da escritura para a produção de um estranhamento do mundo, questionador da própria literatura. Assim, a permanência da literatura se dá na medida em que ela possa morrer (BASTOS, 1998, p. 140).

Dizíamos que a "hermenêutica social" de Jameson complica-se com a situação da literatura em região periférica, à luz da noção de "permanência" de Bastos. Tal "complicar-se" não se deve ao que pode ou não refutar o "inconsciente político", devese ao fato de que Bastos revela a instabilidade existencial da literatura que imane da sua condição ambivalente, antagônica e aporética ${ }^{20}$. Se a literatura, "na iminência de se diluir", tem a sua forma de presença encaminhada para o seu auto-extermínio, então os três horizontes que perfazem a "hermenêutica social" não lidam, apenas, com o "ato simbólico", o "ideologema" e a "ideologia da forma", mas com a iminência de autodiluição e auto-extermínio da literatura ${ }^{21}$.

Se for assim, a interpretação de um texto literário poderia considerar esse "tânatos da literatura" como mais um horizonte interpretativo, uma vez que não se deseje que a "hermenêutica" transcenda a condição instável da literatura, ou, falando kantianamente, o seu "horizonte transcendental", que é "negativo", o que nos sugere um "horizonte hermenêutico negativo", incluindo, como categoria de interpretação, o potencial suicida literário, ou a literatura em direção ao seu auto-extermínio, e o potencial heterocida contra o literário, ou a iminência de a literatura diluir-se, no contexto da sua "permanência" autoquestionadora.

\section{REFERÊNCIAS BIBLIOGRÁFICAS}

\footnotetext{
20 Não dizemos existencial no sentido de "existencialismo" ou "filosofia da existência", mas, tãosomente, no sentido de ser "relativo ou pertencente à existência" (HOUAISS, 2001, p. 1285).

${ }^{21}$ A conclusão de Bastos é radical: "A literatura permanece mas sempre na iminência de se diluir. Esta negatividade é a única forma de sua lucidez, sempre agônica. Ela pode se diluir, ou na indústria cultural, ou na literatura institucionalizada. Permanece enquanto se encaminhar na direção do auto -extermín io" (BASTOS, 1998, p. 140).
} 
BASTOS, Hermenegildo. “A permanência da literatura (direções da prática literária na era do multiculturalismo e da indústria cultural)". In: Cerrados, revista do curso de pós-graduação em literatura. Brasília: Editora Universidade de Brasília, nº 8, ano 7, 1998.

DELEUZE, Gilles e GUATTARI, Félix. $O$ que é a filosofia? Lisboa: Editorial Presença, 1992.

$O$ anti-édipo: capitalismo e esquizofrenia.

Lisboa: Editora Assírio \& Alvim, 1995.

FREUD, Sigmund. "O inconsciente”. In: Escritos sobre a psicologia do inconsciente. Rio de Janeiro: Editora Imago, 2006, volume II. “'Além do princípio do prazer'. In: Escritos sobre a psicologia do inconsciente. Rio de Janeiro: Editora Imago, 2006, volume II.

HEGEL, Georg Wilhelm Friedrich. "A fenomenologia do espírito”. In: Os pensadores. São Paulo: Abril Cultural, 1974.

HEIDEGGER, Martin. Ser e tempo. Petrópolis: Editora Vozes: 2001, parte I. . Seminários de Zollikon. Petrópolis: Editora Vozes, 2001.

HORNBY, A. S. Oxford advanced learner's dictionary of current english. London: Oxford University Presss, 1974.

HOUAISS, Antônio e VILLAR, Mauro de Salles. Dicionário houaiss da língua portuguesa. Rio de Janeiro: Objetiva, 2001.

JAMESON, Fredric. "A interpretação: a literatura como ato socialmente simbólico". In: O inconsciente político: a narrativa como ato socialmente simbólico. São Paulo: Editora Ática, 1992.

KANT, Immanuel. “Crítica da razão pura”. In: Os pensadores. São Paulo: Editora Nova Cultural, 2000.

PALMER, Richard. Hermenêutica. Lisboa: Edições 70, 1996.

REICH, Wilhelm. Materialismo dialético e psicanálise. Lisboa: Editorial Presença, 1977. 